\title{
Ectrópio Cicatricial: Correção com Enxerto de Pele Total
}

\section{Cicatricial Ectropion: Repair with Full-Thickness Skin Graft}

\author{
Ermelindo Tavares ${ }^{1}$
}

PALAVRAS-CHAVE: Cicatriz/cirurgia; Ectrópio/cirurgia; Pálpebras/cirurgia; Transplantação de Pele KEYWORDS: Cicatrix/surgery; Ectropion/surgery; Eyelids/surgery; Skin Transplantation

\section{RELATO DE CASO}

Mulher, 82 anos, caucasiana, submetida à excisão de carcinoma espinocelular da região malar medial superior e pálpebra inferior medial direita e encerramento com retalho malar (avanço e rotação). Registaram-se infeção e deiscência parcial de sutura no pós-operatório. Quatro semanas depois tinha ectrópio cicatricial (EC) generalizado, grave (ponto lacrimal, conjuntiva palpebral e fórnix visíveis) e de grau 1 no teste de flacidez cantal medial e lateral (Fig. 1A). Clinicamente tinha epífora, fotofobia e irritação ocular. A correção cirúrgica com enxerto de pele total (EPT) foi o procedimento preconizado.

A cirurgia foi realizada sob anestesia local. Inseriu-se fio de seda na pálpebra inferior para tração superior da mesma. Procedeu-se à libertação da lamela anterior com incisão paralela à cicatriz (Fig. 1B). Obteve-se um defeito cirúrgico elipsoide que serviu de molde para o enxerto cuja área dadora foi a região pré-auricular. 0 mesmo foi suturado com fio absorvível (Fig. 1C). Por fim, realizou-se antibioterapia tópica e penso (compressivo e oclusivo) com a pálpebra inferior em tração superior até ao sexto dia, altura em que o enxerto se encontrava aderente e viável (Fig. 1D). Aos três meses os resultados estéticos e funcionais eram muito aceitáveis (Fig.s 1E e F).

O EPT é uma boa opção para a correção de EC palpebral inferior de qualquer etiologia. ${ }^{1}$ As outras opções incluem o retalho miocutâneo palpebral superior e a plastia em Z. ${ }^{2-4}$ A combinação com outras técnicas (strip tarsal lateral ou cantopexia) pode ser realizada em alguns casos. ${ }^{5}$ $\bigcirc$ enxerto pode ser colhido na pálpebra superior, na região pré/retroauricular, no pescoço, na fossa supraclavicular e na face interna dos braços. ${ }^{1}$ A primeira constitui a melhor zona dadora devido às suas semelhanças em cor, espessura e textura. ${ }^{1}$ As complicações associadas a 

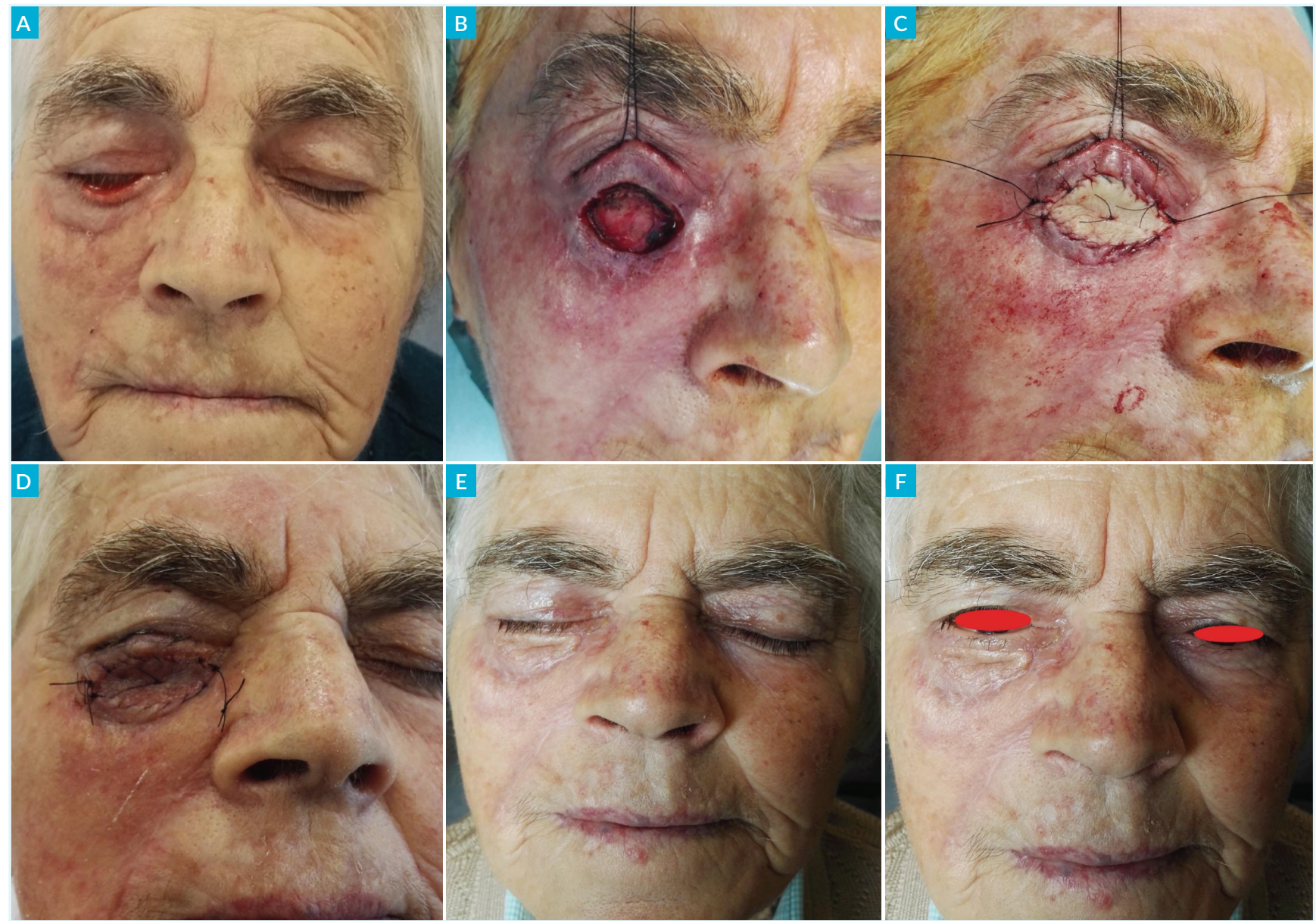

FIGURA 1. Correção cirúrgica de ectrópio cicatricial com enxerto de pele total colhida na região pré-auricular. Infeção e deiscência parcial de sutura no canto interno (zona de pontos ancoragem do retalho malar no periósteo orbitário) resultaram em ectrópio cicatricial (A). Tração palpebral superior com fio de seda e incisão paralela à cicatriz infrapalpebral com libertação da lamela anterior (B). O defeito elipsoide serviu de molde para o enxerto de pele (B). Enxerto adaptado e integrado no defeito (C). Enxerto viável e sem ectrópio ao sexto dia pós-operatório (D). Bom resultado estético e sem ectrópio, três meses depois (E, F).

este procedimento compreendem infeção, hematoma, necrose, despigmentação, ectrópio, contratura e hipertrofia do enxerto. ${ }^{1}$

\section{AGRADECIMENTOS/ ACKNOWLEDGMENTS}

Equipa de enfermagem e assistentes operacionais do bloco operatório e consulta externa.

CONFLITOS DE INTERESSE: Os autores declaram não ter qualquer conflito de interesse na realização do presente trabalho.

FONTES DE FINANCIAMENTO: Não houve qualquer fonte de financiamento na realização do presente trabalho.

CONFIDENCIALIDADE DOS DADOS: Os autores declaram ter seguido os protocolos da sua instituição acerca da publicação dos dados de doentes.

CONFLICTS OF INTEREST: The authors declare that they have no conflicts of interest.
FINANCIAL SUPPORT: This work has not received any contribution, grant or scholarship.

CONFIDENTIALITY OF DATA: The authors declare that they have followed the protocols of their work center on the publication of data from patients.

\section{REFERÊNCIAS}

1. Rathore DS, Chickadasarahilli S, Crossman R, Mehta P, Ahluwalia HS. Full thickness skin grafts in periocular reconstructions: long-term outcomes. Ophthalmic Plast Reconstr Surg. 2014;30:517-20. doi: 10.1097/IOP.0000000000000237.

2. Manku K, Leong JK, Ghabrial R. Cicatricial ectropion: repair with myocutaneous flaps and canthopexy. Clin Exp Ophthalmol. 2006;34:677-81. doi: 10.1111/j.1442-9071.2006.01302.x.

3. Lucci LM, Baldin AC, Da Fonseca Jr NL, Rehder JR. Bipedicle myocutaneous flap for cicatricial ectropion correction. Arq Bras Oftalmol. 2006;69:187-92.

4. Uemura T1, Onizuka T, Suse T, Saiga A, Matsumoto N, Yoshimaru C, et al. Composite Z plasty for cicatricial ectropion of Tessier III cleft. J Craniofac Surg. 2004;15:51-3.

5. Kim HJ, Hayek B, Nasser Q, Esmaeli B. Viability of full-thickness skin grafts used for correction of cicatricial ectropion of lower eyelid in previously irradiated field in the periocular region. Head Neck. 2013;35:103-8. doi: 10.1002/hed.22934. 